\title{
SURGICAL MANAGEMENT OF MENICOCAPSULAR SEPARATION OF THE KNEE JOINT
}

\author{
By
Ahmed Mahmoud Abd El-Twab*, Ahmed Shamma and Mohammed El- Nahas \\ Department of Orthopedic Surgery, Faculty of Medicine, Al-Azhar University \\ *Corresponding author: Ahmed Mahmoud Abdel Twab, \\ Mobile: (+20)01069005600, E-mail: Ahmedtebo10@gmail.com
}

\begin{abstract}
Background: Meniscocapsular separations are longitudinal tears at the meniscocapsular junction of the posterior horn of the medial meniscus. They are commonly associated with the ACL-deficient knee, both in the acute and chronic setting, with their incidence increasing in time from injury. Meniscocapsular separations are difficult to diagnose preoperatively, and one must have a high index of suspicion in the setting of a chronic ACL tear.
\end{abstract}

Objective: To highlighten a special entity of meniscal injuries "meniscocapsular separation".

Patients and Methods: This study included 10 patients with meniscocapsular separation treated between November 2014 and May 2019. All were involved in sporting trauma. Age was between 18 - 40 years. All cases had a minimum 6 months follow-up. All cases had an M.R.I. All patients had medial meniscal tears. During arthroscopy, complete separation of the meniscus at the capsular junction was reported. Reduction was done followed by using the shaver for edge abrasion. An all inside suture technique had been used to repair the meniscus. The Lysholm knee score and International Knee Documentation Committee (IKDC) were recorded to assess functional outcome, and had been recorded before surgery and 6 months after surgery.

Results: Full range of motion was gradually restored. Minimal tenderness was noticed at site of sutures. Four patients had returned to pre-injury activity level. Lysholm knee score improved gradually from preoperatively to final follow-up 6 months later.

Conclusion: Meniscocapsular separation presented as a bucket-handle tear. Vigorous twisting and locking should raise suspicion. M.R.I. may be misleading. Reduction and multiple suture placements from posterior to anterior allowed healing and prevented further displacement.

Keywords: Meniscocapsular separation, meniscal repair, all inside, locking.

\section{INTRODUCTION}

Menisco-capsular separation (MCS) is an avulsion type of injury of the medial and/or lateral meniscus and is defined as detachment of the meniscus from its capsular attachment (Liu et al., 2011). Medial MCS is more frequent than lateral
MCS and most often occurs in combination with other ligament injuries (Chahla et al., 2016). The majority of medial lesions are due to the relative rigid fixation of the medial meniscus to the tibia by the meniscotibial ligament (coronary ligament). This is important for the role the meniscus plays in restraining 
posterior translation of the medial femoral condyle on the tibia (Stephen et al., 2016). Patients with MCS can show relatively unspecific signs of pain, instability and joint effusion. In particular, medial MCS can be associated with other ligamentous injuries. Generally, isolated MCS is known to be an uncommon entity, which is often not or with difficulty diagnosed on MRI scans (Peltier et al., 2015).

The aim of the present work was to highlight a special entity of meniscal injuries - "meniscocapsular separation".

\section{PATIENTS AND METHODS}

This study was performed at AlHussien University Hospital and the patients included in the study were all different types of ground sports, e.g. running, cycling, martial arts and football.

A prospective randomized analytical clinical study was done to assess the efficacy of "'arthroscopic repair of meniscocapsular separation ", in young athletes and its role in their return to their athletic level postoperatively, from November 2014 to May 2019.

This study included 10 patients all of which are athletes, suffering knee injuries during exercise with subsequent knee pains. Examination was performed to all of them and showed a possible meniscal injury. MRI images were done showing meniscocapsular separation injuries.

\section{Patients were selected according the following criteria:}

1. Male or female patient.

2. Age group (18-40).

3. Athlete in a ground sport.

4. Acute and chronic injuries.

All patients were subjected to the following:

A. Preoperative evaluation:

1. Careful history taking

2. Analysis of patient's complaint

3. Clinical examination

4. Radiographic evaluation:-Includes plain X-ray and MRI.

5. Rating scales:-Include

a. Lysholm knee score. (Table 1).

b. International Knee

Documentation Committee score (IKDC).

B. Rehabilitation program: Via basic and advanced physiotherapy exercises.

C. Follow Up evaluation: It included clinical evaluation, postoperative rating scales (Lysholm Knee score and International knee Documentation Committee (IKDC) and statistical analysis.

\section{Statistical analysis:}

Results were expressed as number (\%). Statistical Package for Social Sciences (SPSS) computer program (version 19 windows) was used for data analysis. 


\section{RESULTS}

There were 10 patients with average age between $18-40$ years. Follow-up period averaged 6 months. Pain and swelling improved gradually then subsided. No cases of infection were observed. Minimal tenderness was noticed at site of the sutures, but was tolerated by all patients. Range of motion increased gradually from a mean of $48 \%$ preoperatively to $120 \%$ by 3 months. Full range of motion was safely reached by 6 months in all cases. There was no instability and McMurray test was negative. All cases included in the study before operation showed no locking and no instability, with $80 \%$ had slight limping, $30 \%$ used stick or crutch as support, and $80 \%$ showed slight problem in stairs climbing versus $20 \%$ had one step at a time. As regards pain, all cases complained pain, $50 \%$ had slight problem in squatting and $40 \%$ complained constant swelling (Table 1).

Table (1): Frequency of preoperative Lysholm knee scoring scale assessment among study group $(n=10)$

\begin{tabular}{|c|c|c|c|}
\hline $\begin{array}{ll}\text { Variables } & \text { Lysholm knee scoring scale } \\
\end{array}$ & Score & No & $\%$ \\
\hline \multicolumn{4}{|l|}{ Limp } \\
\hline None & 5 & 2 & $20 \%$ \\
\hline Slight or periodic & 3 & 8 & $80 \%$ \\
\hline \multicolumn{4}{|l|}{ Support } \\
\hline None & 5 & 7 & 70\% \\
\hline Stick or crutch needed & 2 & 3 & $30 \%$ \\
\hline \multicolumn{4}{|l|}{ Locking } \\
\hline None & 15 & 10 & $100 \%$ \\
\hline \multicolumn{4}{|l|}{ Stairs climbing } \\
\hline Slight problem & 6 & 8 & $80 \%$ \\
\hline One step at a time & 3 & 2 & $20 \%$ \\
\hline \multicolumn{4}{|l|}{ Instability } \\
\hline Never & 25 & 10 & $100 \%$ \\
\hline \multicolumn{4}{|l|}{ Pain } \\
\hline None & 25 & $\mathbf{0}$ & $0 \%$ \\
\hline Inconstant and slight during strenuous activities & 20 & 2 & $20 \%$ \\
\hline Marked during or after walking more than $2 \mathrm{k}$ & 15 & 1 & $10 \%$ \\
\hline Marked during or after walking less than $2 \mathrm{~km}$ & 10 & 3 & $30 \%$ \\
\hline Constant & 5 & 3 & $30 \%$ \\
\hline Pain on severe exertion & $\mathbf{0}$ & 1 & $10 \%$ \\
\hline \multicolumn{4}{|l|}{ Swelling } \\
\hline After ordinary activities & 3 & 6 & $60 \%$ \\
\hline Constant & $\mathbf{0}$ & 4 & $40 \%$ \\
\hline \multicolumn{4}{|l|}{ Squatting } \\
\hline No problem & 5 & 5 & $50 \%$ \\
\hline Slight problem & 4 & 5 & $50 \%$ \\
\hline
\end{tabular}


All cases included in the study after operation showed no limping, no locking, and no instability, with $10 \%$ use stick or crutch as support, showed slight problem in stairs climbing and squatting and $10 \%$ complain swelling. After strenuous activities and after ordinary activities, finally $20 \%$ of cases had inconstant and slight pain during strenuous activities (Table 2).

Table (2): Frequency of postoperative Lysholm knee scoring scale assessment among study group $(n=10)$

\begin{tabular}{|l|c|c|c|}
\hline Lariables & Score & No & $\%$ \\
\hline Limb, Locking, Instability & 5 & 10 & $100 \%$ \\
\hline No limping & 15 & 10 & $100 \%$ \\
\hline No locking & 25 & 10 & $100 \%$ \\
\hline No instability & 5 & 9 & $90 \%$ \\
\hline Support & 2 & 1 & $10 \%$ \\
\hline None & 10 & 9 & $90 \%$ \\
\hline Stick or crutch needed & 6 & 1 & $10 \%$ \\
\hline Stairs climbing & 25 & 8 & $80 \%$ \\
\hline No problem & 20 & 2 & $20 \%$ \\
\hline Slight problem & 10 & 8 & $80 \%$ \\
\hline Pain & 6 & 1 & $10 \%$ \\
\hline None & 3 & 1 & $10 \%$ \\
\hline Inconstant and slight during strenuous activities & \multicolumn{1}{|l|}{} \\
\hline Swelling & 5 & 9 & $90 \%$ \\
\hline None & 4 & 1 & $10 \%$ \\
\hline After strenuous activities
\end{tabular}

There is statistically significant low mean in effusion degree and total IKDC score with p-value $<0.05$ after operation, which indicated improvement of cases in effusion after operation. On the other hand there is no statistically significant change with p-value $>0.05$ in degrees of Passive motion deficit (lack of extension and flexion) and quadriceps wasting (Table 3).

Table (3): Comparisons of total IKDC scoring scale pre and postoperative among study group

\begin{tabular}{|c|c|c|c|c|c|}
\hline \multirow{2}{*}{ Groups } & \multicolumn{2}{|c|}{ Preoperative } & \multicolumn{2}{c|}{ Postoperative } & \multirow{2}{*}{ p-value } \\
\cline { 2 - 5 } & Mean & SD & Mean & SD & \\
\hline Effusion & 1.8 & 0.78 & 1.2 & 0.42 & 0.005 \\
\hline Passive motion deficit. & 1.4 & 0.69 & 1 & 0 & 0.1 \\
\hline Lack of flexion & 1.4 & 0.52 & 1.2 & 0.42 & 0.2 \\
\hline Quadriceps Wasting & 1.2 & 0.42 & 1 & 0 & 0.2 \\
\hline Total score & 5.6 & 1.8 & 1 & 0 & $<0.001$ \\
\hline
\end{tabular}


There was a statistically significant improvement with p-value $<0.05$ in effusion degree after operation, as before operation, $60 \%$ of cases had effusion with $\mathrm{B}$, and $\mathrm{C}$ degree, but after operation $80 \%$ of patients had grade A. On the other hand, there was no statistically significant change in degrees of passive motion deficit (lack of extension and flexion) and quadriceps wasting (Table 4).

Table (4): Comparisons of clinical examination pre and postoperative among study group

\begin{tabular}{|c|c|c|c|c|c|}
\hline \multirow{2}{*}{$\begin{array}{l}\text { Clinical } \\
\text { Examination }\end{array}$} & \multicolumn{2}{|c|}{ Preoperative } & \multicolumn{2}{|c|}{ Postoperative } & \multirow{2}{*}{ p-value } \\
\hline & No. & $\%$ & No. & $\%$ & \\
\hline \multicolumn{6}{|l|}{ Effusion } \\
\hline $\mathbf{A}$ & 4 & $40 \%$ & 8 & $80 \%$ & \multirow{3}{*}{0.02} \\
\hline B & 4 & $40 \%$ & 2 & $20 \%$ & \\
\hline $\mathrm{C}$ & 2 & $20 \%$ & 0 & $0 \%$ & \\
\hline \multicolumn{6}{|l|}{ Lack of extension } \\
\hline $\mathbf{A}$ & 7 & $70 \%$ & 10 & $100 \%$ & \multirow{3}{*}{0.1} \\
\hline B & 2 & $20 \%$ & 0 & $0 \%$ & \\
\hline $\mathrm{C}$ & 1 & $10 \%$ & 0 & $0 \%$ & \\
\hline $\mathbf{A}$ & 6 & $60 \%$ & 8 & $80 \%$ & \multirow{2}{*}{0.3} \\
\hline B & 4 & $40 \%$ & 2 & $20 \%$ & \\
\hline \multicolumn{6}{|l|}{ Quadriceps Wasting } \\
\hline A & 8 & $80 \%$ & 10 & $100 \%$ & \multirow{2}{*}{0.1} \\
\hline B & 2 & $20 \%$ & 0 & $0 \%$ & \\
\hline
\end{tabular}
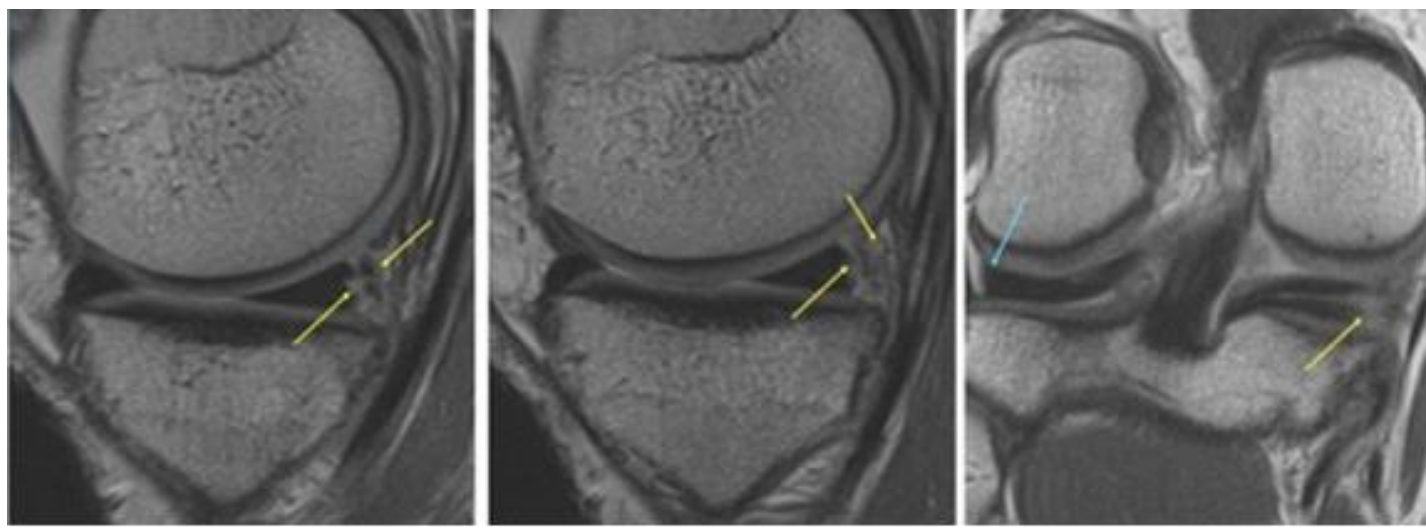

Figure (1): M.R.I knee shows MCS 


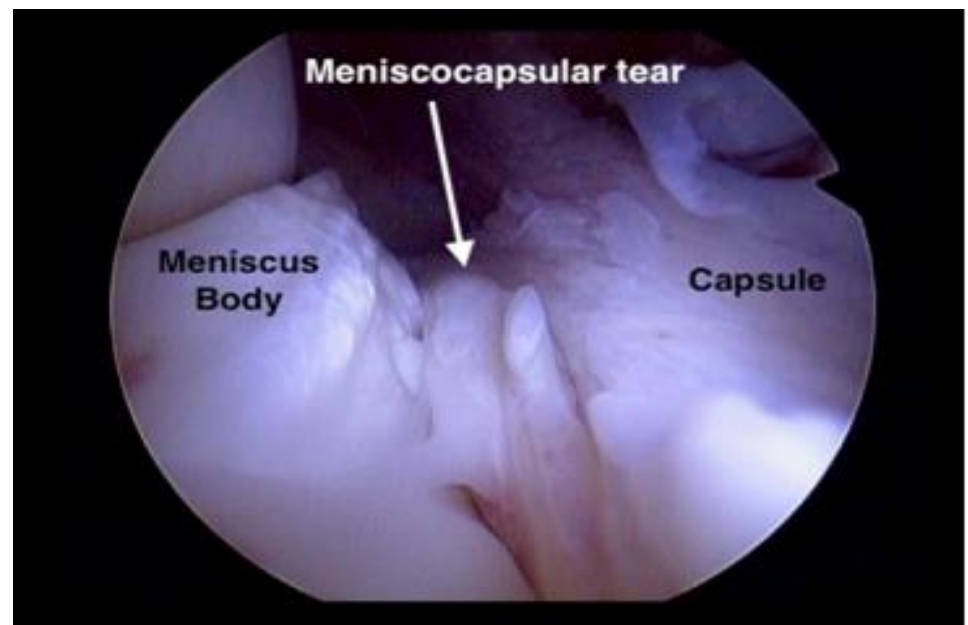

Figure (2): The arthroscope was placed in the posteromedial compartment in a left knee by the Gillquist maneuver. The viewing portal is the anterolateral portal, and the knee is in $90^{\circ}$ of flexion. Identification of meniscocapsular lesions is better appreciated with this technique.

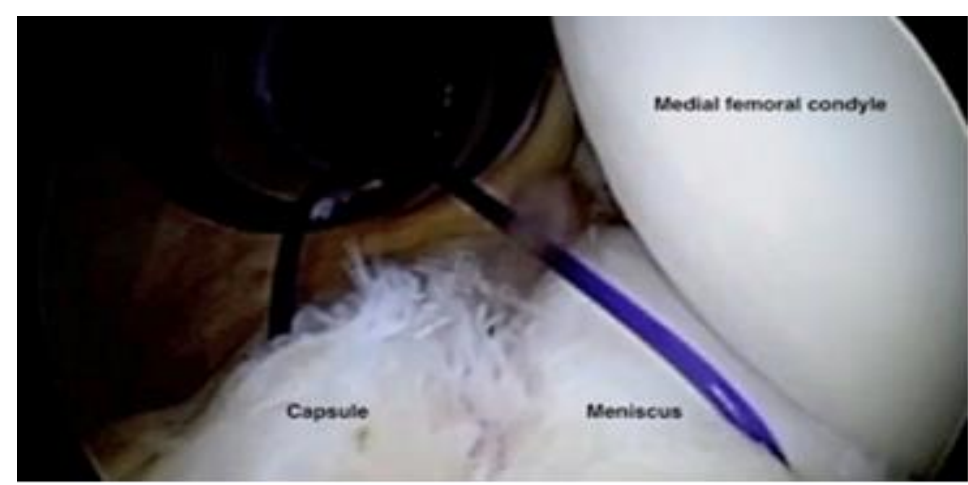

Fig. (3): Visualization of the posteromedial compartment from the anterolateral portal in a right knee in $90^{\circ}$ of flexion. A No. 0 polydioxanone sulfate suture is passed through the suture hook and retrieved with a grasper from the posteromedial portal.
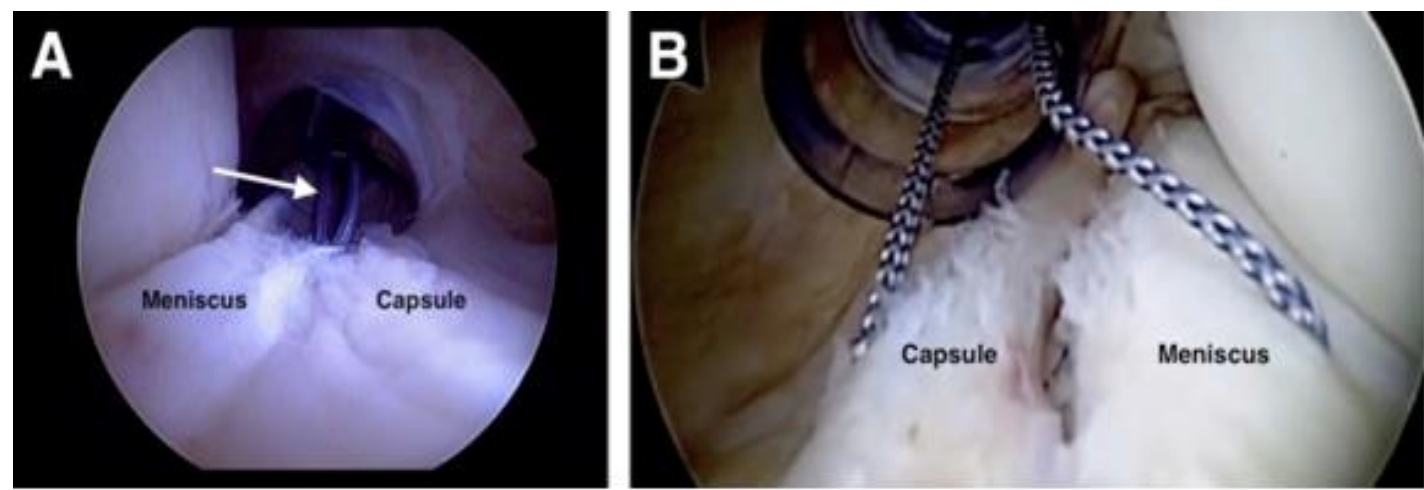

Fig. (4): (A) Visualization of the posteromedial compartment from the anterolateral portal in a left knee in $90^{\circ}$ of flexion. A No. 2 Orthocord suture (arrow) is passed through the meniscal and capsular tissue. (B) Visualization of the posteromedial compartment from the anterolateral portal in a right knee in $90^{\circ}$ of flexion. Suture passage is visualized with the arthroscope in the anterolateral portal. 


\section{DISCUSSION}

The meniscus has functional importance in respect of load transmission in the knees, stability, shock absorption, proprioception, protection of the joint cartilage and lubrication (Maak et al., 2012). There is a universal consensus regarding preserving the meniscus among orthopedic surgeons. The meniscocapsular region has good healing potential due an abundant blood supply. Different suturing techniques have been described in literature, including inside-out, outside-in and all-inside (Papalia et al., 2013).

Meniscocapsular separation occurs in the tibial part of the meniscus. Most meniscocapsular separations are seen together with micro-trauma and ACL tears. With increasing severity of trauma, a longitudinal separation pattern develops (Bollen, 2010).

Inside-out repair of meniscal tears is the gold standard in respect of biomechanical strength. As the needle diameter is small in the application of this technique, there is less damage to the meniscus. In addition, as the meniscus is biomechanically fixed to the capsule in a circular manner, it does not cause femoral elevation of the meniscus. However, the need for posteromedial and posterolateral incisions is a disadvantage (Ahn et al., 2011).

The modified Gillquist maneuver consistently allows the surgeon to view the posterior compartment without placing the MFC articular cartilage at risk of iatrogenic injury. Using a $70^{\circ}$ arthroscope can significantly improve visualization of the entire lesion, in particular inferior capsular displacement typical of these injuries (Hutchinson et al., 2014).
Furthermore; spinal needle localization in conjunction with the $70^{\circ}$ arthroscope ensures the PM portal allows access to the entire tear. A significant advantage of the all-inside technique using a Spectrum hook through the PM portal is that it allows the surgeon to titrate the amount of tissue grasped for repair. Such a technique ensures a stable repair without over constraining the capsule. The capsular tissue is often displaced distally from the meniscocapsular junction. This technique allows for proximal advancement of the tissue for an anatomic repair, aiding in the reapproximation of the natural mechanics of the knee (Duchman et al., 2015). Direct visualization of the tear with the $70^{\circ}$ arthroscope enhances the ability to anatomically repair the PMC lesion. Furthermore, no special implants are required for this technique, which may improve cost-effectiveness compared with other methods (Bollen, 2010).

It has been reported that sutures applied to the capsule cause discomfort after repair by all-inside devices. This could be due to inappropriate suture anchor placement. In our previous applications, patients experienced feelings of tension and pulling, but now, using the suturing technique applied from the tibial surface of the meniscus as here described, no problems of feeling postoperative tension or pulling have been developed in any patient.

In conclusion, the suturing method applied from the tibial section of the meniscus does not disrupt the anatomic position of the meniscus in meniscocapsular separation. Thus, the optimum conditions are provided for restoration of the functions of the 
meniscus. This technique may be helpful in obtaining better clinical results.

\section{CONCLUSION}

Mensicocapsular repair is a valuable operation in treating mensicocapsular separation in young athletes and can ensure their return safely to their sports on the short term aspect.

\section{REFERENCES}

1. Ahn JH, Bae TS, Kang KS, Kang SY and Lee SH. (2011): Longitudinal tear of the medial meniscus posterior horn in the anterior cruciate ligament-deficient knee significantly influences anterior stability. Am. J. Sports Med., 39(10):2187-2193.

2. Bollen SR. (2010): Posteromedial meniscocapsular injury associated with rupture of the anterior cruciate ligament: a previously unrecognised association. J. Bone Joint Surg. Br., 92(2):222-223.

3. Chahla J, Dean CS, Moatshe G, Mitchell JJ, Cram TR and Yacuzzi C. (2016): Meniscal ramp lesions: anatomy, incidence, diagnosis, and treatment. Orthop J Sports Med., 4(7):232245.

4. Duchman KR, Westermann RW, Spindler KP, ReinkeEK, Huston LJ and Amendola A, (2015): The fate of meniscus tears left in situ at the time of anterior cruciate ligament reconstruction: a 6-year follow-up study from the MOONcohort. Am J Sports

Med.;43(11):2688-95

5. Hutchinson ID, Moran CJ, Potter HG, Warren RF and Rodeo SA (2014): Restoration of the meniscus: form and function. Am J Sports Med. 42(4):987-98

6. Liu X, Feng H, Zhang H, Hong L, Wang XS and Zhang J. (2011): Arthroscopic prevalence of ramp lesion in 868patients with anterior cruciate ligament injury. Am J Sports Med., 39(4):832-7.

7. Maak TG, Fabricant PD and Wickiewicz TL. (2012): Indications for meniscus repair. Clin Sports Med., 31(1):1-14.

8. Papalia R, Vasta S, Franceschi F, D'Adamio S, Maffulli N and Denaro V. (2013): Meniscal root tears: from basic science to ultimate surgery. Br. Med. Bull., 106:91-115.

9. Peltier A, Lording TD, Lustig S, Servien E, Maubisson $L$ and Neyret $P$. (2015): Posteromedial meniscal tears may be missed during anterior cruciate ligament reconstruction. Arthroscopy, 31(4):691-8.

10. Stephen JM, Halewood C, Kittl C, Bollen SR, Williams A and Amis AA. (2016): Posteromedial meniscocapsular lesions increase tibiofemoral joint laxity with anterior cruciate ligament deficiency, and their repair reduces laxity. Am J Sports Med., 44(2):400-8. 
التدبير الجراحي لانفصال كبسول الركبة عن الغضروف الهلالي أحمد محمود عبد التواب، أحمد شما، محمد النحاس الاس التهن

قسم جراحة العظام، كلية طب، جامعة الأزهر

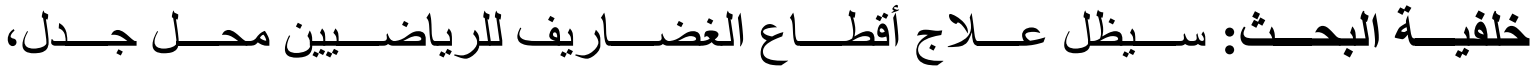

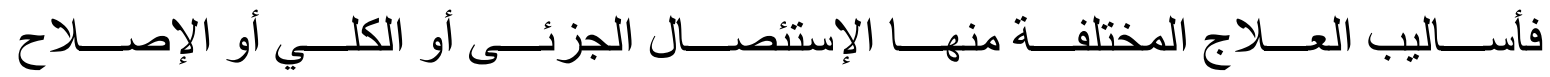

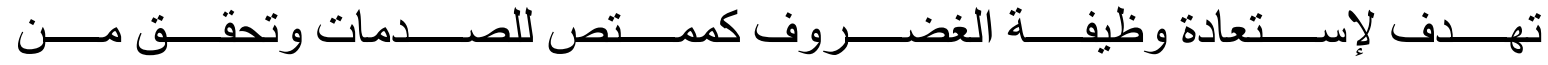
كبسول الركبة عائد وظيفى جيد للرياضى المصاب.

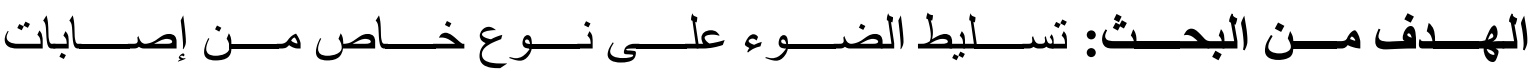
الغضروف "إنفصال الغضروف الهلالي".

المرضــي وطــق البحــث: شـــت الدر اســـة 10 مرضـــى يعـانون مــن إنفصــال الغضــروف الهلالــي عـن كبســول الركبـة فــى الفئـة العمريــة مـن 18 إلـى 40

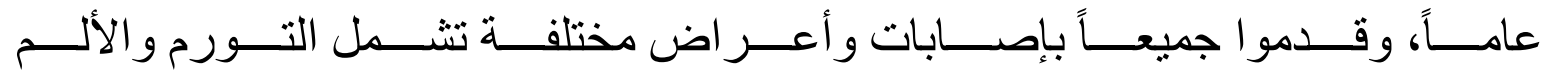

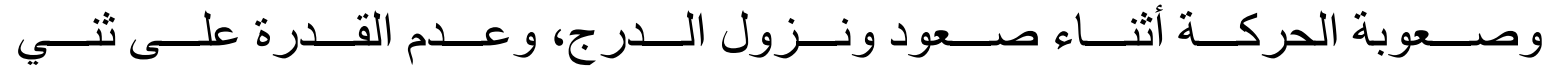

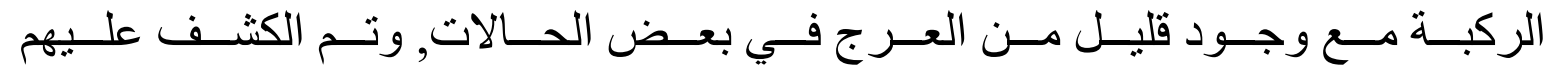

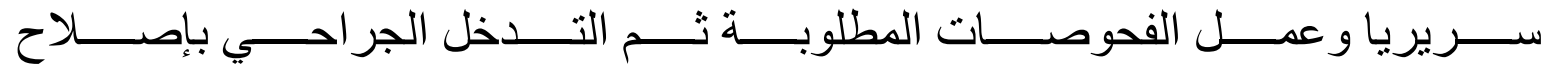

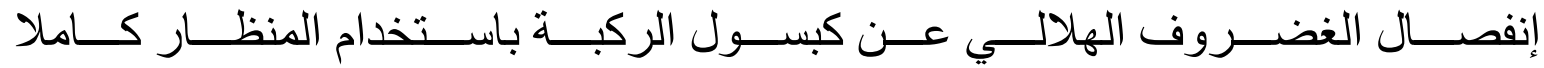
من داخل المفصل وتم متابعتهم لمدة ستة أشهر بعد الجر احة.

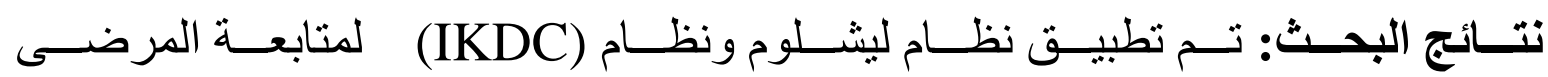

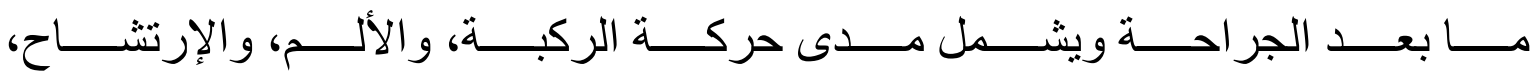

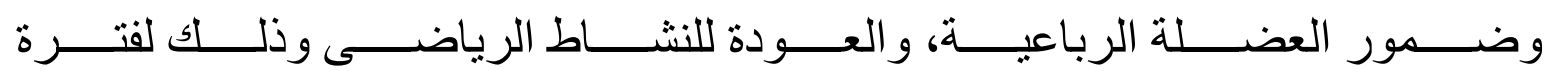

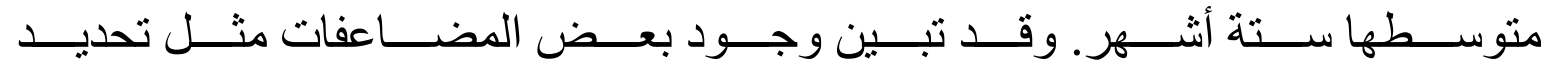

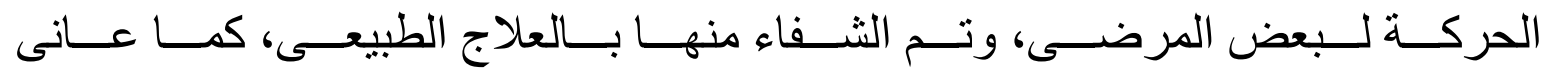

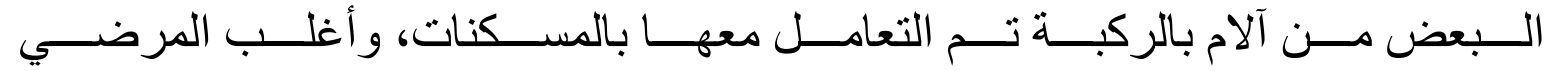




\section{AHMED MAHMOUD ABD EL-TWAB et al.,}

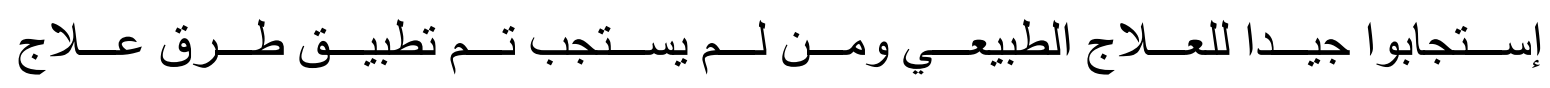

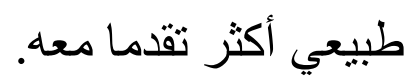

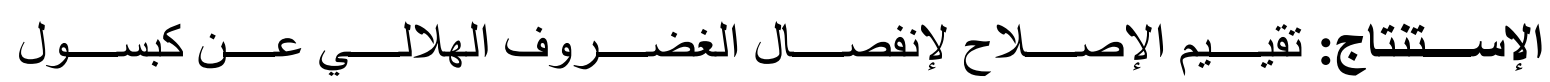

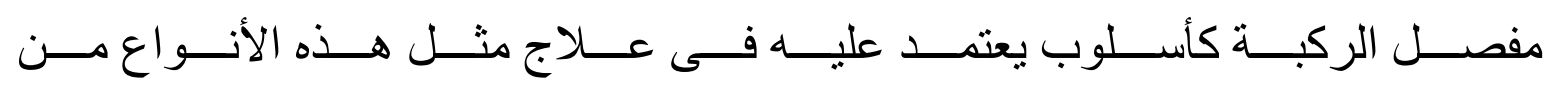

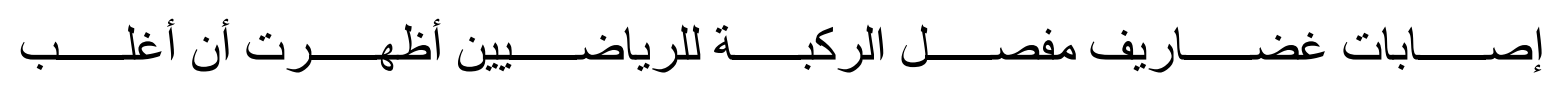
المرضى عادو ا بشكل طبيعى لنشاطهم الرياضي بعد الجر احة. 